\title{
Evaluación In Vitro de la capacidad probiótica de bacterias ácido lácticas aisladas de heces de cuyes (Cavia porcellus) de un Centro Experimental
}

\author{
In vitro evaluation of probiotic capability of acid lactic bacteria from guinea pig (Cavia porcellus) feces of an \\ Experimental Center
}

Carla Serrano $^{1}$, Luis M. Jara ${ }^{1}$, Lilia Chauca ${ }^{2}$, Carlos Shiva ${ }^{1}$

\section{RESUMEN}

El presente estudio evaluó la capacidad probiótica in vitro de 150 bacterias ácido lácticas (BAL) aisladas de heces de tres razas de cuyes provenientes de un Centro Experimental de crianza intensiva, mediante ensayos in vitro en agar que evaluaron la capacidad de actividad enzimática amilolítica, proteolítica, celulolítica y antagonismo frente a Salmonella sp. patogénica. Las cepas BAL que lograron algún resultado positivo a alguno de los ensayos in vitro fueron evaluadas para la supervivencia a $\mathrm{pH}$ 2.0, 4.0 y bilis al 0.3\%. Se obtuvieron cepas Gram positivas, 93.3\% de ellas con morfología bacilar y 6.7\% con morfología ovoide. El 38.7\% de cepas demostró capacidad de degradar almidón soluble, el $66.7 \%$ para proteínas de leche y el 4\% para carboximetilcelulosa sódica. Solo el 5.3\% de cepas tuvo acción antagónica frente a Salmonella sp. La frecuencia de cepas según raza en relación a la degradación amilolítica y proteolítica demostró tener asociación estadística significativa. Se destaca además la capacidad de supervivencia de las cepas evaluadas por cada raza, donde se obtuvo en cada ensayo una frecuencia mayor al $40 \%$. Se resalta el potencial probiótico de BAL autóctonas aisladas de heces de cuyes que podrían ser evaluadas a futuro en ensayos de campo.

PALABRAS CLAVE: Cavia porcellus, probióticos, bacterias ácido lácticas, cuyes.

\section{SUMMARY}

The present study evaluated the in vitro probiotic capacity of 150 lactic acid bacteria (BAL) isolated from feces of three breeds of guinea pigs from an Experimental Center of intensive rearing, by means of in vitro tests on agar that evaluated the capacity of amylolytic, proteolytic enzymatic activity, cellulolytic and antagonism against pathogenic Salmonella sp. The BAL strains that achieved a positive result in any of the in vitro tests were evaluated for survival at $\mathrm{pH} 2.0,4.0$ and $0.3 \%$ bile. Gram positive strains were obtained, 93.3\% of them with bacillary morphology and $6.7 \%$ with ovoid morphology. $38.7 \%$ of strains showed the ability to degrade soluble starch, $66.7 \%$ for milk proteins and $4 \%$ for sodium carboxymethyl cellulose. Only $5.3 \%$ of strains had an antagonistic action against Salmonella $\mathrm{sp}$. The frequency of strains according to race in relation to amylolytic and proteolytic degradation proved to have a significant statistical association. The survival capacity of the strains evaluated by each breed is also highlighted, where a frequency greater than $40 \%$ was obtained in each trial. The probiotic potential of native BAL isolated from feces of guinea pigs that would be evaluated in future field trials is highlighted.

KEYWORDS: Cavia porcellus, probiotics, acid lactic bacteria, guinea pigs.

Universidad Peruana Cayetano Heredia. Lima, Perú.

Instituto de Innovación Agraria (INIA) - Proyecto cuyes. Lima, Perú. 


\section{INTRODUCCIÓN}

El cuy (Cavia porcellus) es un mamífero roedor herbívoro, monogástrico, de ciclo reproductivo corto y nativo de la región andina de Sudamérica, cuya producción de carne es considerada una actividad pecuaria con posibilidad de generar utilidades. La intensificación en su producción ha conllevado a una mayor incidencia de enfermedades, que se ven en su mayoría directamente relacionadas con la densidad e inadecuado manejo sanitario (Chuquizuta y Morales, 2017). Por ejemplo, la salmonelosis causada en la mayoría de casos por Salmonella entérica serovar Typhimurium, es considerada en el Perú como la enfermedad de mayor importancia por su alta morbilidad $(52.7 \%)$ y mortalidad $(95 \%)$ (Morales, 2017). En la búsqueda de opciones para el control sanitario general se han implementado alternativas como administración de forma preventiva de dosis bajas de antibióticos como promotores de crecimiento. A su vez la antibioterapia para tratar enfermedades infecciosas bacterianas puede generar problemas de rechazo comercial a carne con residuos y resistencia de cepas a antibióticos que podrían ocasionar falla terapéutica futura (Torres y Zarazaga, 2002; Bengtsson y Greko, 2014).

Los probióticos se definen como todo aquel microorganismo vivo que al ser administrado en cantidades adecuadas confiere un beneficio a la salud integral del huésped (Food and Agriculture Organization of the United Nations [FAO], 2002). Éstos pueden utilizarse como una herramienta complementaria a la dieta para mejorar la conversión alimenticia, aumento de peso, además de prevenir enfermedades entéricas por medio de diferentes mecanismos (Bernardeau et al., 2006). Pueden ser clasificados según su origen como bacteriano o no bacteriano, y/o alóctonos o autóctonos de la microbiota intestinal (FAO, 2016). Las bacterias ácido lácticas (BAL) constituyen un grupo de bacterias comúnmente utilizadas como probióticos; en cuyes, se han probado diferentes consorcios bacterianos aislados de la microbiota intestinal en las que se destacan Enterococcus hirae, L. reuteri, L. johnsonii, Streptococcus thoraltensis y Bacillus pumilus, las cuales tuvieron un efecto positivo en la conversión alimenticia (Torres et al., 2013).

Para el desarrollo de los probióticos se estipulan pautas y pruebas que deben pasar de forma in vitro para que sea considerado posteriormente como benéfico. Algunas de estas pruebas incluyen la tolerancia a microambientes o ensayos que asemejen las condiciones del tracto gastrointestinal, resistencia a sales biliares, capacidad de adherencia a mucosa y antagónica frente a patógenos (FAO, 2002).

Existen pocas investigaciones sobre la evaluación probiótica de cepas autóctonas y alóctonas del tracto gastrointestinal de cuyes; actualmente se ha investigado principalmente la aplicación in vivo de Lactobacillus sobre los parámetros productivos o en la morfología intestinal (Gonzales, 2018; Cano, 2016). En ese contexto, el presente estudio evaluó in vitro el potencial de cepas BAL aisladas de heces de cuyes de las razas Perú, Andina e Inti para la capacidad de antagonizar el crecimiento de Salmonella sp., degradar almidón, proteína, celulosa, y tolerancia a algunas condiciones gastrointestinales.

\section{MATERIAL Y MÉTODOS}

El estudio fue de naturaleza observacional descriptiva. La recolección de muestras fue realizada durante el mes de junio del 2019, en el galpón de Cuyes reproductores de las razas Perú, Andina e Inti, pertenecientes al Instituto Nacional de Innovación Agraria (INIA), Lima. El procesamiento de las muestras fue realizado en el Laboratorio de Nutrición Animal e Inocuidad Alimentaria, Facultad de Medicina Veterinaria y Zootecnia, Universidad Peruana Cayetano Heredia. El estudio fue aprobado por el Comité Institucional de Ética para el Uso de Animales (CIEA) de la Universidad Peruana Cayetano Heredia-Constancia 043-06-19.

Para el muestreo por conveniencia fueron consideradas aquellas "pozas" con cuyes reproductores, preferiblemente con crías lactantes, en donde todos los animales estuvieran clínicamente sanos, sin registro de enfermedad o signos con 2 semanas previas al muestreo. Fueron excluidas aquellas "pozas" en las que los cuyes fueron tratados con antibióticos al menos 2 semanas previas al muestreo.

Fueron seleccionadas 10 "pozas" por raza, de cada una se recolectó un aproximado de 10 gr. de heces presuntamente frescas en un frasco estéril. Para el transporte fue utilizado un contenedor cooler acondicionado con paquetes de gel refrigerante a $4^{\circ} \mathrm{C}$ aproximadamente, para el traslado de las muestras hasta el laboratorio dentro de las primeras 4 horas. 


\section{Aislamiento e identificación microbiológica presuntiva de bacterias ácido lácticas (BAL)}

Las muestras de heces fueron homogeneizadas en $50 \mathrm{ml}$ de suero fisiológico $(\mathrm{NaCl} 0.9 \%)$ estéril y mezcladas con un mazo de mortero previamente desinfectado. Cien (100) $\mu \mathrm{L}$ del homogenizado fue colocado en $5 \mathrm{ml}$ de caldo Man, Rogosa y Sharpe (MRS; Difco, Francia) e incubado durante 24 horas a $37^{\circ} \mathrm{C}$ en condiciones de microaerofilia $\left(4-5 \% \mathrm{CO}_{2}\right.$ $1-2 \% \mathrm{O}_{2}$ ) con el uso de una vela encendida dentro de una jarra hermética (Saha et al., 2016). La siembra con un asa microbiológica fue por agotamiento sobre una placa con agar MRS, para ser incubada bajo las mismas condiciones descritas anteriormente. Se seleccionaron 5 colonias por cada placa, considerando aquellas con aspecto transparente y blanquecino cremoso, de crecimiento individual aislado (Cueto y Aragón, 2012). La identificación preliminar del total de 150 colonias seleccionadas fue realizada con tinción Gram y prueba de catalasa.

\section{Evaluación del potencial probiótico in vitro de cepas BAL seleccionadas}

Capacidad antagónica frente a Salmonella sp.

La actividad antagónica frente a Salmonella sp. fue realizada con el método modificado de difusión por cilindros sobre agar Müeller Hinton (MH). Sobre un agar MH se sembró en tres direcciones una suspensión a escala Mc Farland $0.5(625 \mathrm{~nm})$ de un aislado clínico de Salmonella sp. de cuyes (perteneciente al cepario del Laboratorio de Nutrición Animal e Inocuidad Alimentaria). Seguidamente se realizaron pocillos sobre el agar que fueron cortados con una punta de micropipeta de $100 \mu \mathrm{L}$, que fueron llenados con 70 $\mu \mathrm{L}$ de sobrenadante del cultivo líquido overnight de cada BAL (centrifugados previamente a $2500 \mathrm{rpm}$ por 5 minutos). El agar fue puesto a reposar a $4^{\circ} \mathrm{C}$ por 10 minutos y luego se incubó a $28^{\circ} \mathrm{C}$ por $24 \mathrm{~h}$ en condiciones aerobias. La lectura de la actividad antagónica del sobrenadante fue realizada mediante la medición del diámetro en milímetros del halo de inhibición formado alrededor de los pocillos (Hassanzadazar et al., 2012).

\section{Capacidad de actividad enzimática}

\section{Actividad proteolítica}

Se utilizó un agar a base de leche parcialmente descremada en polvo (Nestlé ${ }^{\circledR}$ Carnation ${ }^{\circledR}$, EEUU) al 1.5\% en agar Tripticasa de Soya (TSA; HIMEDIA, India). Se colocó $2 \mu \mathrm{L}$ de caldo MRS overnight de cada cepa BAL aislada previamente, y se incubó a $37^{\circ} \mathrm{C}$ por $24 \mathrm{~h}$. en condiciones de microaerofilia. La lectura de la capacidad de actividad enzimática fue realizada por observación directa de un halo transparente de degradación alrededor de la colonia crecida en el agar (Asaduzzaman et al., 2018). Como control positivo fue utilizada una cepa comercial de Bacillus subtilis ATCC $19659^{\mathrm{TM}}$ dada su conocida capacidad en la industria alimentaria como productor de proteasas.

\section{Actividad amilolítica}

Se utilizó un agar a base de almidón soluble (HiMedia, India) al $1 \%$ en agar TSA. Se colocaron $2 \mu \mathrm{L}$ de caldo MRS de cada cepa BAL incubada overnight en las condiciones descritas anteriormente. La capacidad de actividad enzimática fue evaluada agregando lugol de Gram (Diagtest, Perú) directamente sobre la placa, revelando un halo de degradación/ consumo del almidón en el agar (Asaduzzaman et al., 2018). Para esta prueba fue considerado también como resultado positivo aquellas cepas donde se apareció un halo circunscrito por debajo de la colonia, el cual fue observado realizando un raspado con un asa de siembra en el área de crecimiento. Como control positivo fue utilizado de la misma manera Bacillus subtilis ATCC $19659^{\mathrm{TM}}$.

\section{Actividad celulolítica}

Se utilizó un agar a base de Carboximetilcelulosa sódica (CMC-Na; Sigma Aldrich, EEUU) donde se colocaron $2 \mu \mathrm{L}$ de caldo MRS de cada cepa BAL incubada bajo las mismas condiciones que los ensayos anteriores. La capacidad de actividad celulolítica fue evaluada colocando lugol de Gram (Diagtest, Perú) directamente sobre la placa durante 5 minutos, revelando un halo de degradación o consumo de celulosa del agar (Asaduzzaman et al., 2018; Kasana et al., 2008). Como control positivo se utilizó una cepa comercial de Streptomyces spp. ATCC 25507тM conocido por su capacidad de producir enzimas con acción sobre celulosa (Hu et al., 2012).

\section{Pruebas de supervivencia a condiciones gastrointestinales}

Para evaluar la capacidad de supervivencia in vitro a algunas condiciones que simulen el tracto gastrointestinal de cuy, se evaluaron sólo las cepas BAL que lograron tener un resultado positivo a alguno 
de los ensayos de actividad enzimática descritos anteriormente.

\section{Tolerancia a diferentes niveles de $\mathrm{pH}$}

Las cepas BAL seleccionadas fueron colocadas en caldo MRS y se incubaron como se ha descrito anteriormente. Luego fueron llevadas a escala Mc Farland 0.5 en $\mathrm{NaCl} 0.9 \%$ estéril, obteniendo una suspensión bacteriana aproximada de $1.5 \times 10^{8} \mathrm{UFC/}$ $\mathrm{ml}$. Luego, a cada suspensión de cepas se le realizó diluciones seriadas en hasta llegar a $10^{4} \mathrm{UFC} / \mathrm{ml}$ en suero estéril con $\mathrm{pH}$ ajustado a 2.0 y 4.0. De esta última dilución se extrajeron $0.1 \mathrm{ml}$ y se colocaron en pocillos de microplacas de fondo plano, los cuales fueron incubados por 3 horas a $37^{\circ} \mathrm{C}$ en microaerofilia. Al término del tiempo de incubación, el contenido de cada pocillo fue sembrado por la técnica de diseminación en placas MRS individuales, para luego incubarlas por $48 \mathrm{~h}$ a $37^{\circ} \mathrm{C}$ en condiciones de microaerofilia. Posteriormente, se realizó el conteo de colonias y el porcentaje de supervivencia de acuerdo a lo descrito por Cueto-Vigil et al. (2010). Se determinó como tolerantes a aquellas que obtuvieron algún porcentaje mayor a $0.00 \%$ de supervivencia.

\section{Tolerancia a sales biliares}

La bilis utilizada para este ensayo fue colectada de la vesícula biliar de cuyes beneficiados para comercialización dentro de las instalaciones del INIA. Ésta fue filtrada con un disco de membrana de $0.45 \mu \mathrm{m}$ descartable (Puradisc ${ }^{\mathrm{TM}}$, Whatman ${ }^{\mathrm{TM}}$ ) en un ambiente estéril, para ser luego ser almacenada a $-20^{\circ} \mathrm{C}$ hasta su posterior uso. Similar al ensayo anterior, las cepas seleccionadas en caldo MRS con crecimiento de 24 horas a $37^{\circ} \mathrm{C}$ en condiciones de microaerofilia fueron llevadas a escala Mc Farland 0.5 en suero fisiológico estéril pH 7.0 con bilis al $0.3 \%$ (Hassanzadazar et al., 2012), para luego ser diluidas hasta llegar a una concentración de $10^{4} \mathrm{UFC} / \mathrm{ml}$. De esta última dilución se tomaron $0.1 \mathrm{ml} \mathrm{y}$ fueron puestos en pocillos de microplacas de fondo plano, para ser dejados a incubar por 3 horas a $37^{\circ} \mathrm{C}$ en microaerofilia. Posteriormente, el contenido de cada pocillo fue sembrado por diseminación en placas MRS individuales, y llevado a cultivo por 48 horas a $37^{\circ} \mathrm{C}$ en condiciones de microaerofilia. El recuento de cepas viables fue hallado de similar forma que en el ensayo anterior.

\section{Análisis de resultados}

Los resultados se colocaron en tablas de frecuencia para estadística descriptiva. Para evaluar la asociación estadística entre la frecuencia de aislados BAL según la raza y la capacidad enzimática o antagonista se utilizó la prueba de Chi-cuadrado y test exacto de Fisher con el programa WinEpi (Universidad de Zaragoza, España) y STATA (Ver. 14.0), respectivamente, con un nivel de significancia de 0.05 .

\section{RESULTADOS}

Se seleccionaron un total de 150 cepas Gram positivas, de las cuales el $93.3 \%$ tuvo morfología bacilar y el $6.7 \%$ morfología ovoide, además que el $89.3 \%$ resultó catalasa negativa. Se encontró que solo el $5.3 \%$ de cepas presentó actividad antagónica frente a Salmonella sp., el $66.1 \%$ degradación proteolítica, $38.7 \%$ amilolítica y $4 \%$ celulolítica (tabla 1 ).

Se observó que la raza Andina tuvo mayor frecuencia de aislados BAL con antagonismo frente a Salmonella sp; la raza Perú una mayor frecuencia de aislados con actividad amilolítica y proteolítica, y la raza Inti una mayor frecuencia de aislados con actividad celulolítica. Se encontró además asociación estadística significativa entre la frecuencia de aislados según raza y la frecuencia de aisladas con degradación amilolítica $(\mathrm{p}<0.0001)$ y proteolítica $(\mathrm{p}<0.0001)$.

Un total de 119 cepas BAL presentaron al menos un resultado positivo de actividad enzimática o antagónica in vitro. En cuanto a la capacidad de tolerancia a

Tabla 1. Frecuencia de cepas con actividad probiótica in vitro según raza de cuy $(\mathrm{n}=150)$

Frecuencia de cepas según raza

\begin{tabular}{ccccc}
\hline Prueba probiótica & Perú (\%) & Andina (\%) & Inti (\%) & Total (\%) \\
\hline Amilolítico & $18,0(27 / 150)$ & $16,0(24 / 150)$ & $4,7(7 / 150)$ & $38,7(58 / 150)$ \\
Proteolítico & $32,7(49 / 150)$ & $16,7(25 / 150)$ & $16,7(25 / 150)$ & $66,1(99 / 150)$ \\
Celulolítico & 0,0 & $0,7(1 / 150)$ & $3,3(5 / 150)$ & $4,0(6 / 150)$ \\
Antagonismo & $1,3(2 / 150)$ & $4,0(6 / 150)$ & 0,0 & $5,3(8 / 150)$ \\
\hline
\end{tabular}


Tabla 2. Frecuencia de cepas con tolerancia a diferentes condiciones gastrointestinales in vitro (Perú $n=50$; Andina $n=40$; Inti $n=29$ )

\begin{tabular}{cccc}
\hline \multicolumn{4}{c}{ Cepas tolerantes según condición hostil (\%) } \\
\hline Razas de cuy & $\mathbf{p H ~ 2 , 0}$ & $\mathbf{p H ~ 4 , 0}$ & Bilis 0.3\% \\
\hline Perú & $76(38 / 50)$ & $86(43 / 50)$ & $76(38 / 50)$ \\
Andina & $50(20 / 40)$ & $55(22 / 40)$ & $75(30 / 40)$ \\
Inti & $44,8(13 / 29)$ & $96,5(28 / 29)$ & $89,6(26 / 29)$ \\
\hline
\end{tabular}

diferentes condiciones gastrointestinales in vitro, en la Tabla 2 se muestra la frecuencia de las 119 cepas distribuidas por raza que lograron sobrevivir a cada ensayo de tolerancia. En los tres ensayos diferentes de tolerancia se observó que los aislados BAL de la raza Perú e Inti tuvieron la mayor frecuencia de cepas capaces de sobrevivir a las condiciones hostiles evaluadas ( $\mathrm{pH}$ bajo y acción biliar).

\section{DISCUSIÓN}

Con respecto al potencial antagónico frente a patógenos, especialmente entéricos, la capacidad in vitro de producir mayor diámetro de halo podría ser deducido de la relación directamente proporcional al número de bacterias probióticas en suspensión. Esto no necesariamente se cumple ya que en el presente estudio se evidenció que suspensiones de BAL con baja densidad óptica de crecimiento lograron tener mayor halo de degradación o inhibición. Por lo que la capacidad de antagonismo puede no solo depender del rápido crecimiento exponencial de las bacterias, sino del propio compuesto antagónico podría estar presente y de la especie de BAL productora del mismo, como se ha descrito para el ácido acético, o bacteriocinas (Bermudez-Brito et al., 2012). Los mecanismos antagónicos se deben principalmente a compuestos a base de biocinas extracelulares con actividad antimicrobiana que desestabilizan la membrana citoplasmática bacteriana, además de ciertos ácidos orgánicos que reducen el pH e inhiben el crecimiento de patógenos (Mohankumar, 2011).

Se observó una mayor frecuencia de cepas BAL de la raza Perú que tuvieron capacidad proteolítica y amilolítica in vitro. Esto podría considerarse para futuros estudios in vivo, ya que esta raza es considerada la más precoz y con mayor facilidad de ganancia de peso. Asimismo, tal como lo sugiere Cano et al. (2016), la inclusión de una suspensión de bacterias del género Lactobacillus-BifidobacteriumSaccharomyces en la dieta de cuyes puede generar una mejora en la ganancia de peso e índice de conversión alimenticia en la etapa de crecimiento y acabado. Así también, la inclusión de cepas con capacidad de degradación amilolítica podría contribuir con la digestión de carbohidratos, algo importante en la etapa de lactación donde existen limitaciones en la función del páncreas aún en desarrollo (García, 2012).

Por otro lado, un exceso de celulosa en la dieta puede conllevar al cese completo de ingesta de alimento, además de distención del tracto gastrointestinal (Condori, 2014). La adición de microorganismos probióticos capaces de degradar la celulosa como $B$. pumillus, B. succinogenes y $R$. flavefaciens, podrían prevenir este tipo de situaciones adversas (Meryandini et al., 2011).

Para los ensayos de supervivencia, los $\mathrm{pH}$ fueron ajustados a niveles bajos para simular condiciones de hostilidad gastrointestinal, en donde los resultados demostraron que en todos los aislados BAL de las diferentes razas la frecuencia de cepas tolerantes fue mayor al 44\%. La capacidad de supervivencia de cepas potencialmente probióticas ha sido reportada en otros estudios, entre ellos se menciona al género Lactobacillus con capacidad de tolerar a condiciones de pH 2.5 por $4 \mathrm{~h}$ (Corcoran et al., 2005). Sobre ello, se han reportado algunas proteínas de superficie de ciertas cepas de Lactobacillus que podrian estar relacionadas al crecimiento y supervivencia a niveles de pH bajo (Nezhad et al., 2010).

Sobre la supervivencia a sales biliares, este ensayo contribuye a una evaluación adicional de otras condiciones de estrés bacteriano en el intestino delgado. Sin embargo, si bien las evaluaciones in vitro simulan las condiciones gastrointestinales, estas no garantizan la tolerancia in vivo, por lo que es necesario evaluar otras condiciones como la adición de proteasas y la adhesión a la mucosa intestinal. Para contrarrestar posibles bajas en la supervivencia, no se excluye la posibilidad del uso de algún encapsulado, liofilizado, entre otros, que podrían aumentar las probabilidades de supervivencia durante tránsito 
gastrointestinal. Para ello se requieren ensayos de campo donde se evalúe el compuesto biológico vía oral en el alimento o agua de bebida.

Existen estudios que describen el uso de consorcios de cepas BAL aplicados frente a patógenos con la finalidad de potenciar o complementar las propiedades benéficas de cada cepa aislada, ya sea mediante la exclusión competitiva o la producción de compuestos antagónicos (Bhola y Bhadekar, 2019). Los resultados obtenidos en el presente estudio demandan la identificación y caracterización de las cepas BAL o de sus compuestos que tengan capacidad antagónica, para una correcta evaluación en campo que contribuya a la reducción de los casos de infecciones entéricas en cuyes. Es recomendable además la evaluación de la inocuidad de las cepas, además de su capacidad de adquirir/transmitir plásmidos de resistencia antimicrobiana y efectos adversos que puedan tener en los animales vivos antes de realizar ensayos en campo.

\section{CONCLUSIONES}

Las heces de cuy representan una fuente de BAL con potencial probiótico in vitro.

Al menos una BAL autóctona de cuy tuvo la capacidad in vitro de degradar en conjunto compuestos de proteínas, almidones y celulosa.

La frecuencia de cepas que degradaron almidón y proteína in vitro estuvo asociada significativamente a la raza de cuyes.

Cepas BAL aisladas de la raza Perú y Andina tuvieron la mayor frecuencia de capacidad antagónica frente a Salmonella sp.

Al menos una BAL autóctona de cuy tuvo la capacidad in vitro de tolerar condiciones hostiles como diferentes $\mathrm{pH}$ y sales biliares.

\section{Correspondencia}

Carla Serrano

Correo electrónico: patricia.serr9@gmail.com

\section{REFERENCIAS BIBLIOGRÁFICAS}

1. Asaduzzaman, M., Iehata, S., Akter, S., Kader, M., Ghosh, S., Khan, M. \& Abol-Munafi, A. (2018). Effects of host gut-derived probiotic bacteria on gut morphology, microbiota composition and volatile short chain fatty acids production of Malaysian Mahseer Tor tambroides. Aquaculture Reports. 9, 5361. https://doi.org/10.1016/j.aqrep.2017.12.003

2. Bengtsson, B., \& Greko, C. (2014). Antibiotic resistance--consequences for animal health, welfare, and food production. Upsala journal of medical sciences, 119(2), 96-102. https://doi.org/10.3109/030 09734.2014.901445

3. Bermudez-Brito, M., Plaza-Díaz, J., MuñozQuezada, S., Gómez-Llorente, C. \& Gil, A. (2012). Probiotic Mechanisms of Action. Annals of Nutrition \& Metabolism. 61(1), 160-174. doi: 10.1159/000342079.

4. Bernardeau, M., Guguen, M., \& Vernoux, J. P. (2006). Beneficial lactobacilli in food and feed: long-term use, biodiversity and proposals for specific and realistic safety assessments. FEMS Microbiology Reviews, 30(4), 487-513. doi: https://doi.org/10.1111/ j.1574-6976.2006.00020.x

5. Bhola, J. \& Bhadekar, R. (2019). Actividad sinérgica invitro de bacterias del ácido láctico contra estafilococos resistentes a múltiples fármacos. $B M C$ medicina complementaria y alternativa , 19 (1), 70. https://doi.org/10.1186/s12906-019-2470-3

6. Cano, J., Carcelén, F., Ara, M., Quevedo, W., Alvarado, A.,\& Jiménez, R. (2016). Efecto de la Suplementación con una Mezcla Probiótica sobre el Comportamiento Productivo de Cuyes (Cavia porcellus) durante la Fase de Crecimiento y Acabado. Revista de Investigaciones Veterinarias del Perú, 27(1), 51-58. doi: https://doi.org/10.15381/rivep. v27i1.11458.

7. Chuquizuta, C. \& Morales, S., (2017). Identificación de agentes bacterianos aislados de gazapos muertos de cuyes en una granja de crianza intensiva en Lima, Perú. Revista Electronica de Veterinaria, 18 (12), 13.

8. Condori, R. (2014). Evaluación de bajos niveles de fibra en dietas de inicio y crecimiento de cuyes (Cavia porcellus) con exclusión de forraje. [Tesis de pregrado]. Universidad Nacional Agraria La Molina.

9. Corcoran, B., Stanton, C., Fitzgerald, G., Ross, R. (2005). Survival of Probiotic Lactobacilli in Acidic Environments Is Enhanced in the Presence of Metabolizable Sugars. Applied and Environmental Microbiology, 71 (1), 3060-3067. https://doi. org/10.1128/AEM.71.6.3060-3067.2005.

10. Cueto, C., y Aragón, S. (2012). Evaluation of probiotic potential of lactic acid bacteria to reduce in vitro cholesterol. Scientia Agropecuaria,1, 45-50. https://doi.org/10.17268/sci.agropecu.2012.01.06

11. Cueto-Vigil, M., Acuña-Monsalve, Y., \& ValenzuelaRiaño, J., (2010). Evaluación in vitro del potencial probiótico de bacterias ácido lácticas aisladas de suero costeño. Scientific Electronic Library Online, 32(93), 129-138. http://www.scielo.org.co/pdf/acbi/ 
v32n93/v32n93a1.pdf

12. Food and Agriculture Organization of the United Nations. (2016). Probiotics in animal nutrition Production, impact and regulation by Yadav $\mathrm{S}$. Bajagai, Athol V. Klieve, Peter J. Dart and Wayne L. Bryden. Editor Harinder P.S. Makkar. FAO Animal Production and Health Paper No. 179. Rome.

13. Food and Agriculture Organization of the United Nations. (2002). Guidelines for the Evaluation of Probiotics in Food. FAO/WHO. https://www.who. int/foodsafety/fs_management/en/probiotic guidelines.pdf

14. García, M. (2012). Caracterización de la actividad de las enzimas hidroliticas localizadas en la región cecal de cuyes (Cavia porcellus). [Tesis de pregrado]. Universidad Nacional Mayor de San Marcos.

15. Gonzales, L. (2018). Efecto de los probióticos, prebióticos y simbióticos sobre la morfología intestinal y parámetros sanguíneos (serie eritrocítica y serie leucocítica) en cuyes (Cavia porcellus) de engorde desafiados con Salmonella Typhimurium. [Tesis de pregrado]. Universidad Nacional Mayor de San Marcos.

16. Hassanzadazar, H., Ehsani, A., Mardani, K. \& Hesari, J., (2012). Investigation of antibacterial, acid and bile tolerance properties of lactobacilli isolated from Koozeh cheese. Veterinary research forum: An international quarterly journal, 3(3), 181-185.

17. Hu, C., Liu, L., \& Yang, S. (2012). Protein enrichment, cellulase production and in vitro digestion improvement of pangolagrass with solid state fermentation. Journal Of Microbiology, Immunology And Infection, 45(1), 7-14. doi: https://doi. org/10.1016/j.jmii.2011.09.022

18. Kasana, R., Salwan, R., Dhar, H., Dutt, S. \& Gulati, A. (2008). A Rapid and Easy Method for the Detection of Microbial Cellulases on Agar Plates
Using Gram's Iodine. Current Microbiology, 57(5), 503-507. doi: https://doi.org/10.1007/s00284-0089276-8

19. Meryandini, A., Melani, V., \& Sunarti, T. (2011). Addition of cellulolytic bacteria to improved the quality of fermented cassava flour. African Journal of Food Science and Technology. 2(2): 030-035.

20. Mohankumar, A. (2011). Characterization and antibacterial activity of bacteriocin producing Lactobacillus isolated from raw cattle milk sample. International Journal of Biology, 3(3), 128-143.

21. Morales, S. (2017). Patógenos bacterianos y parasitarios más frecuentes en cuyes de crianza familiar - comercial en tres distritos de la Provincia de Bolognesi, Departamento de Ancash en época de seca. [Tesis de maestría]. Universidad Nacional Mayor de San Marcos.

22. Nezhad, M.H., Stenzel, D.,\& Britz, M. (2010). Effect of growth at low $\mathrm{pH}$ on the cell surface properties of a typical strain of Lactobacillus casei group. Iranian Journal of Microbiology, 2(3), 144151.

23. Saha, U. S., Misra, R., Tiwari, D., \& Prasad, K. N. (2016). A cost-effective anaerobic culture method $\&$ its comparison with a standard method. The Indian journal of medical research, 144(4), 611-613. https:// doi.org/10.4103/0971-5916.200881

24. Torres, C. \& Zarazaga, M. (2002). Antibióticos como promotores del crecimiento en animales. ¿Vamos por el buen camino? Gaceta Sanitaria 16(2): 109-12.

25. Torres, C., Carcelén, F., Ara, M., San Martín, F., Jiménez, R., Quevedo, W. \& Rodríguez J. (2013). Efecto de la suplementación de una cepa probiótica sobre los parámetros productivos del cuy (Cavia porcellus). Revista de Investigación Veterinaria del Perú, 24(4), 433-440. https://doi.org/10.15381/rivep. v24i4.2729. 